\title{
UM ESTUDO DE CASO SOBRE O ENSINO DE INGLES POR MEIO DA ABORDAGEM (ESP)
}

\author{
A CASE STUDY ON ENGLISH TEACHING THROUGH THE ESP APPROACH
}

\author{
Suellen Cordovil da Silva ${ }^{1}$ \\ Maria Auxiliadora da Silva ${ }^{2}$
}

RESUMO: O objetivo desta pesquisa é investigar a coerência do ensino da Língua Inglesa por meio da abordagem ESP nos cursos ofertados pelo Idioma sem Fronteiras na UNIFESSPA, no qual tem como público alvo os discentes, estes que necessitam do inglês para finalidades acadêmicas, assim como para pleitear programas de mobilidade estudantil. Este estudo se direciona a delimitar conceitos sobre os processos da internacionalização na educação superior, a importância da Língua Inglesa à (nível) internacional e o seu ensino para fins específicos de acordo com os autores: kirsch (2015), Gattolin e Navarro (2016), Lamri (2016), Vilaça (2003), e outros. E ainda a fazer observações sobre a implantação das novas políticas linguísticas, através da criação do núcleo de línguas inglesa (NucLi) do programa Idioma sem Fronteiras na UNIFESSPA; a partir do levantamento de dados dos quais serão: análises bibliográficas e documentais; observações de aulas no NucLi; entrevista com professores; revisão de material didático e sua coerência em relação à abordagem EPS.

Palavras-chave: Internacionalização no ensino superior; Idiomas sem Fronteiras; English for Specific Purpose (ESP); Mobilidade acadêmica.

ABSTRACT: The objective of this research is to investigate the coherence of the teaching of the English Language through the ESP approach in the courses offered by Language without Borders at UNIFESSPA, in which the target audience is students, who need English for academic purposes, as well as to plead student mobility programs. This study aims to delimit concepts about the processes of internationalization in higher education, the importance of the English Language at (international) level and its teaching for specific purposes according to the authors: kirsch (2015), Gattolin and Navarro (2016), Lamri (2016), Vilaça (2003), and others. And also making comments on the implementation of new language policies, through the creation of the English language nucleus (NucLi) of the Language without Borders program at UNIFESSPA; from the survey of data, which will be: bibliographic and documentary analyzes; class observations at NucLi; interview with teachers; revision of teaching material and its coherence in relation to the EPS approach.

Keywords: Internationalization in higher education; Languages without Borders; English for Specific Purpose (ESP); Academic mobility.

\section{Introdução}

As universidades públicas brasileiras, gradativamente alcançam novos espaços e visibilidade internacional com a internacionalização da educação. Zicman (2007) afirma que estamos em um intenso processo de internacionalização das práticas sociais, globalização, parcerias, intercâmbios e redes que se interligam especialmente com as novas tecnologias da comunicação e da informa-

\footnotetext{
${ }^{1}$ Doutoranda na Universidade Federal de Santa Maria UFSM, Professora Assistente de Literatura de Língua Inglesa na Universidade Federal do Sul e Sudeste do Pará. E-mail: sue ellen11@yahoo.com.br

2 Graduada em Letra Inglês pela Universidade Federal do Sul e Sudeste do Pará - UNIFESSPA. E-mail: liasilva2009@gmail.com
} 
ção. Nesta perspectiva, o Governo Federal brasileiro criou em 26 de julho de 2011 o programa de pesquisa Ciências Sem Fronteiras (CsF) com o propósito de promover a consolidação, expansão e internacionalização da ciência, tecnologia, inovação e competitividade brasileira por meio do intercâmbio e da mobilidade internacional.

A iniciativa deste programa é fruto de esforço conjunto dos Ministérios da Ciência,

Tecnologia e Inovação (MCTI) e do Ministério da Educação (MEC), por meio de suas respectivas instituições de fomento - Conselho Nacional de Desenvolvimento Científico e Tecnológico (CNPq) e Comissão de Aperfeiçoamento de Pessoal do Nível Superior (Capes) e Secretarias de Ensino Superior e de Ensino Tecnológico do MEC.

Inicialmente em 2011, o Governo Brasileiro, estimou a distribuição de até 101 mil bolsas em quatro anos para promover intercâmbio de alunos de graduação e pós-graduação ao exterior com a finalidade de manter contato com universidades competitivas em relação à tecnologia e inovação.

O programa CsF tem por objetivo ainda, atrair pesquisadores do exterior que se dispõem, a se fixar no Brasil ou estabelecer parcerias com os pesquisadores brasileiros nas áreas prioritárias definidas no Programa.

A universidade é um campo que integra saberes científicos do mundo inteiro, assim, potencializa as capacidades tecnológicas e de desenvolvimento de um país. Hudzik considera que "a internacionalização se intensifica com a globalização do comércio, com as forças crescentes da sociedade, trocas de ideias e com a mobilidade estudantil." (HUDZIK 2011, p.1).

A mobilidade acadêmica ganhou força com a criação do programa CsF, que se mostrou positivo para alavancar o país rumo à internacionalização das universidades brasileiras, embora, posteriormente, tenha-se identificado a necessidade de dar suporte aos intercambistas acadêmicos, em relação ao aprendizado de línguas, por isso, surgiu o programa Idiomas Sem fronteiras.

O Governo Federal implementou o idioma sem fronteiras (IsF), desenvolvido também pelo MEC por intermédio da Secretaria de Educação Superior (SESu) em conjunto com a CAPES, com o propósito maior de incentivar o aprendizado de línguas dentro das universidades e favorecer uma mudança abrangente e estruturante no ensino de idiomas estrangeiros no país; ensinar, intensificar e motivar o aprendizado de línguas, e incentivar a mobilidade estudantil.

Este relato de experiência traz informações pertinentes ao processo de internacionalização da Universidade Federal do Sul e sudeste do Pará (UNIFESSPA), mostra a importância de oferecer cursos de Língua Inglesa (LI) para alunos de graduação; dedicou-se a encontrar elementos que evidenciassem a relevância do método Inglês para Fins Específicos (ESP), nas aulas do Núcleo de Língua Inglesa (NucLi). Essa abordagem está desenvolvida com todos os cursos deste período.

O objetivo geral desta pesquisa é analisar a coerência no ensino da Língua Inglesa por meio dos fundamentos da abordagem de ensino, English for Specific Purpose (ESP), inglês para fins específicos, nos cursos ofertados pelo idioma sem Fronteiras na UNIFESSPA. Os objetivos específicos estão direcionados ao o levantamento de conceitos da abordagem English for Specific Purpose (ESP); da implantação do programa Idiomas sem Fronteiras; e o estudo sobre a finalidade do processo de apropriação das competências e habilidades adquiridas pelos alunos, ao aprenderem inglês nas aulas do Núcleo de Língua Inglesa (NucLi).

Esta pesquisa se justifica, pela relevância em dominar a língua inglesa na graduação, visto ser, a língua Inglesa, a língua franca da academia, onde os estudantes necessitam do inglês; para submeter trabalhos científicos em língua inglesa, para terem acesso a mais quantidades de conteúdos, assim como, para pleitear intercâmbios com universidades estrangeiras.

Os resultados desta pesquisa busca contribuir para a visualização de experiências de sala de aula com alunos graduandos no aprendizado de idioma estrangeiro, trazer reflexões sobre o ensino de línguas nas universidades, e porventura contribuir com a fundamentação de políticas de ensino de línguas para o público acadêmico. No primeiro tópico, estão apresentados conceitos sobre o Inglês para Fins Específicos, no segundo; tem-se uma breve apresentação do programa Idiomas sem Fronteiras na universidade; por seguinte as informações sobre o NucLi da Universi-

https://periodicos.unifap.br/index.php/letras

Macapá, v. 9, n. 3, $2^{\circ}$ sem., 2019 
dade Federal do Sul e sudeste do Pará, e a análise e resultados desse relato.

\section{Inglês para Fins Específicos (ESP): como surgiram as primei- ras ideias e por qual motivo?}

Segundo Lamri (2016), por volta do período da guerra fria, estudiosos assumiram um novo direcionamento no ensino de línguas estrangeiras, com o propósito de orientar o ensino para objetivos específicos dos aprendizes, de forma que atendessem as exigências crescentes nas áreas econômicas, técnicas e científicas para se formar profissionais bilíngues. A partir de então, o ensino de línguas estrangeiras direcionou-se a atender as necessidades especificas de aprendizes de forma que correspondesse aos objetivos de cada um em dominar uma segunda língua.

Lamri (2016) relata que, alguns pesquisadores conscientes das mudanças no mundo, iniciaram estudos voltados ao ensino e aprendizagem de uma linguagem para situações práticas da vida cotidiana, a partir da época da guerra fria em diante, reorganizando, e criando novas abordagens, adaptando o ensino aprendizagem ao uso do corpus específico para cada área, direcionando-as conforme necessidades de cada aprendiz.

O Inglês para Fins Específicos (ESP) representa ter um motivo, uma razão específica para aprender uma língua estrangeira. Nesta linha de considerações, Hutchinson e Waters (1987) argumentam que no método ESP, a opinião dos aprendizes é relevante e não deve ser ignorada, pois o que se entende por necessidade é o uso da língua em uma situação específica.

Segundo Vilaça (2010), o método English for Specific Purpose (ESP), observa-se uma prioridade nas habilidades e conhecimentos, delimitados com base no levantamento das necessidades dos alunos, enquanto que, o método de ensino, Inglês Geral, engloba, amplia, o desenvolvimento das quatro habilidades linguísticas por meio de estudos estruturais, lexicais e comunicativos em geral.

A despeito disso Hutchinson e Waters (1987) consideram que o que faz a diferença entre o English for Specific Purpose (ESP) do Inglês Geral (EG), não é a necessidade do aluno, e sim a consciência que se tem sobre as necessidades, pois, em todos os casos existe algum tipo de interesse em aprender a língua, seja para usar no trabalho ou simplesmente para passar de ano na instituição escolar.

Lamri (2016) destaca que a abordagem de ensino ESP é conhecida por ser centrada no aprendiz e as necessidades e metas desses alunos são de valor supremo, enquanto a abordagem de Inglês Geral é centrada na linguagem e se concentra em aprender a língua a partir de uma ampla percepção abrangendo todas as habilidades linguísticas e culturais. As abordagens de ensino ESP segue o mesmo sistema estrutural que qualquer outro modelo de ensino de línguas, embora siga a abordagem de provocar o ensino para a necessidade que o aprendiz tem em adquiri-la. Ainda, Lamri (2016) cita o modelo de Dudley-Evans e St. Johns (1998), onde estes autores definem que as principais etapas do ESP são as análises das necessidades, o desenho do curso, a seleção e produção de materiais, o ensino e a aprendizagem e a avaliação. Segundo Dudley-Evans e St. John (1998), o ESP foi se consolidando em um sistema de progressão contínua de aprimoramento, para atender às necessidades dos aprendizes. Desde então se tornou uma atividade inovadora no ensino de línguas estrangeiras.

\section{A implantação do Programa Idiomas Sem Fronteiras na UNIFESSPA}

O Programa Idiomas sem Fronteiras ${ }^{3}$ foi instituído pela Portaria no 973, de 14 de novem-

\footnotetext{
${ }^{3}$ http://isf.mec.gov.br/: Desenvolvido pelo Ministério da Educação (MEC) por intermédio da Secretaria de Educação Superior (SESu) em conjunto com a Coordenação de Aperfeiçoamento de Pessoal de Nível Superior (CAPES). Acesso em: 14/09/2016.
} 
bro de 2014, elaborado com o objetivo de proporcionar oportunidades de acesso a universidades de países onde a educação superior é conduzida em sua totalidade ou em parte por meio da língua inglesa. Para suprir a necessidade de estudantes e professores em alcançar um nível de competência no aprendizado de línguas, gerando uma mudança no ensino de idiomas estrangeiros no Brasil.

O Idiomas sem Fronteiras visa dar suporte para os alunos que pretendem serem futuros intercambistas e ainda capacitar alunos estrangeiros com cursos de língua portuguesa. A previsão do Ministério da Educação é que sete idiomas façam parte do programa, entre eles: Inglês, Francês, Espanhol, Italiano, Japonês, Mandarim e Alemão. Cada universidade federal ou entidade que participar do programa com cursos terá um núcleo responsável pelo gerenciamento das aulas presenciais e pelas bolsas disponíveis a graduandos do curso de Letras (Língua Inglesa) que estejam aptos a se tornarem instrutores no programa, além de poder realizar testes de proficiência da língua que darão direito a certificado.

O Idiomas sem Fronteiras geral foi inicialmente implantado para complementar o Ciências sem Fronteiras e às demais políticas públicas de internacionalização, está diretamente empenhado em atender a comunidade acadêmica em geral. Dessa forma, o Idiomas sem Fronteiras geral tem buscado se institucionalizar como uma nova política de ensino de línguas estrangeiras nas instituições de ensino superior pelo país.

Até o ano deste estudo, o programa está inserido de forma ativa em 38 universidades pelo país, e a Universidade Federal do Sul e Sudeste do Pará (UNIFESSPA) está entre essas. Ela tem sede no município de Marabá, teve sua abertura oficial em seis de junho de 2013, a partir da estrutura da Universidade Federal do Pará (UFPA), tendo como base o desmembramento do Campus de Marabá da UFPA, o qual já contava com maturidade acadêmica para recepcionar a nova instituição de ensino superior e receber o programa Idiomas Sem Fronteiras.

A Universidade federal do Sul e Sudeste do Pará recebeu o programa em 2015, inicialmente de forma gradativa, o que fez com que adotasse estratégias de divulgação por vários meios, de forma criativa e convincente que demonstrassem além da credibilidade vinculada a instituição, também evidenciasse a importância do domínio de inglês no meio cientifico. Nesta universidade, o programa Idiomas sem Fronteiras funciona de forma gratuita, oferece cursos presencias e online com testes de proficiência de reconhecimento internacional e cursos online. Atualmente o teste de proficiência aplicado na Universidade Federal do Sul e Sudeste do Pará é o Toefl ITP (Test of English as a foreign language/integral transformative practice - Teste de inglês como língua estrangeira/prática transformadora integral).

As inscrições são realizadas no site oficial do Idioma sem fronteiras ${ }^{4}$. Podem se inscreverem nos cursos, alunos de graduação, mestrado, doutorado, matriculados nas universidades públicas e privadas credenciadas no programa, profissionais técnicos das universidades e professores de idiomas da rede pública também podem participar.

Os cursos presenciais de línguas acontecem nas universidades federais credenciadas ao programa. Como critérios de matrícula, o aluno pode realizar curso de apenas um idioma por vez, e caso haja desistência, o aluno não poderá se inscrever novamente por um determinado tempo.

Os cursos são oferecidos nas duas modalidades de ensino, presencial e a Educação à Distância (EAD) de forma desvinculada. A UNIFESSPA, oferece nesta fase inicial, cursos de inglês, na modalidade presencial através do NucLi - Núcleo de Línguas Inglesa, órgão regulador e responsável pelo Ensino de línguas estrangeiras do Idioma sem Fronteiras e ainda pela modalidade EAD - ensino de línguas online, através do My English Online.

O My English Online - MEO é o curso de inglês online do Programa Idiomas sem Fronteiras, por uma iniciativa do MEC e da Capes destinada aos alunos de graduação e pós-graduação de

\footnotetext{
4 http://isfaluno.mec.gov.br/ Acesso em: 14/11/2016.
} 
instituições de ensino superiores públicas e privadas brasileiras. O curso My English Online é baseado na ferramenta para ensino de idiomas, que oferece aos usuários um pacote completo de atividades interativas para o estudo da língua inglesa em qualquer horário e em qualquer lugar.

Os cursos trabalham a compreensão oral e escrita, o vocabulário e a gramática da

língua. Após o aluno se inscrever, e fazer o nivelamento, ele irá aprender os conteúdos por níveis, se obter avaliação positiva, passará para os demais níveis. O aluno terá o prazo de 4 meses para a conclusão dos cursos EAD.

O usuário terá acesso a livros interativos, leituras de textos acadêmicos (National Geographic), exercícios de gramática (com correção imediata), dicionários, atividades para prática oral e testes de acompanhamento. O curso é dividido em cinco níveis de aprendizado. Cada nível contém três partes abrangendo atividades com e-book, vídeo, gramática e leituras. Ao final de cada parte, o usuário deverá fazer um teste de progresso como preparação para a prova final do nível.

Podem participar do My English, os alunos de graduação de instituições públicas de ensino superior, alunos de graduação de instituições privadas de ensino superior, desde que tenham obtido acima de 600 pontos no ENEM, nos exames realizados a partir de 2009 e alunos de pósgraduação stricto sensu, mestrado e doutorado recomendados pela CAPES.

\section{O NUCLI na Universidade Federal do Sul e Sudeste do Pará de 2015 a 2016}

O Núcleo de língua Inglesa (NucLi) é o Departamento responsável por oferecer o ensino de língua Inglesa a estudantes universitários e servidores (técnicos e professores) e pela aplicação dos testes de proficiência em Inglês Toefl-ITP. A portaria no 973 de 14 de Novembro de 2014, institui o Programa Idiomas sem Fronteiras e dá outras Providências, nessas quais no artigo 11 estão apresentadas, quanto ao ensino presencial da língua, dispondo às universidades, adotar políticas de ensino condizentes com o programa. Assim as universidades podem adotar metodologias e estratégias de ensino adequadas ao programa para o ensino de língua nas aulas presenciais.

Em 2014 a UNIFESSPA, abre as primeiras turmas de inglês, com a oferta de cursos presenciais. Para os cursos presenciais, o aluno deverá fazer a inscrição através o site do Idiomas sem Fronteiras e realizar o teste de nivelamento da língua, Toefl-ITP. Os cursos presenciais tem a duração de 16, 34, 48 e 64 horas de aula. Esta variação depende do nível de proficiência de cada turma. O corpo docente do NucLi é composto pelos alunos de graduação em letras inglesa, que obtiverem nota acima de 7,5 no nivelamento. Iniciaram-se as atividades com três instrutores bolsistas e em 2016, o NucLi permaneceu com apenas um professor para as turmas presenciais.

Por normas instituídas nos editais da Capes, o quadro de professores deve ser composto por alunos da graduação em Licenciatura - Inglês do curso de Letras, que apresentam proficiência em inglês correspondente aos níveis $\mathrm{C} 1$, em maioria, e alguns B2.

Apresentamos agora um dos relatórios analítico, do IsF da UNIFESSPA de 2016, onde indica dados quantitativos da comunidade acadêmica a das provas aplicadas desde a institucionalização da universidade como centro aplicador do Toefl. Os dados abaixo indicam $20 \%$ de provas corrigidas, sobre a comunidade acadêmica; estudantes, docentes e técnicos administrativos, realizaram a prova do Toefl ITP desde sua primeira oferta, no ano de 2014 até 2016.

Tabela: 1 Comunidade Acadêmica da Universidade Federal do Sul e Sudeste do Pará (UNIFESSPA)

\begin{tabular}{|l|l|l|}
\hline Número de estudantes & (Censo 2015): & 742 \\
\hline Número de docentes & (Censo 2015): & 79 \\
\hline Número de técnico-administrativos & (Censo 2015): & 06 \\
\hline Número total de provas de TOEFL corrigidas: & 20\% (do total da comunidade universitária) & 42 \\
\hline
\end{tabular}

Fonte: Relatório Analítico sobre o Idiomas sem Fronteiras na UNIFESSPA de 2016 
Para realizar os cursos presenciais oferecidos pelo NucLi, é necessário que os interessados realizem as provas do Toefl. Apresenta-se a seguir o histórico de ofertas do Toefl desde 2014.

Gráfico 1: Demonstrativo de Ofertas da Prova do Toefl ITP da Universidade Federal do Sul e Sudeste do Pará

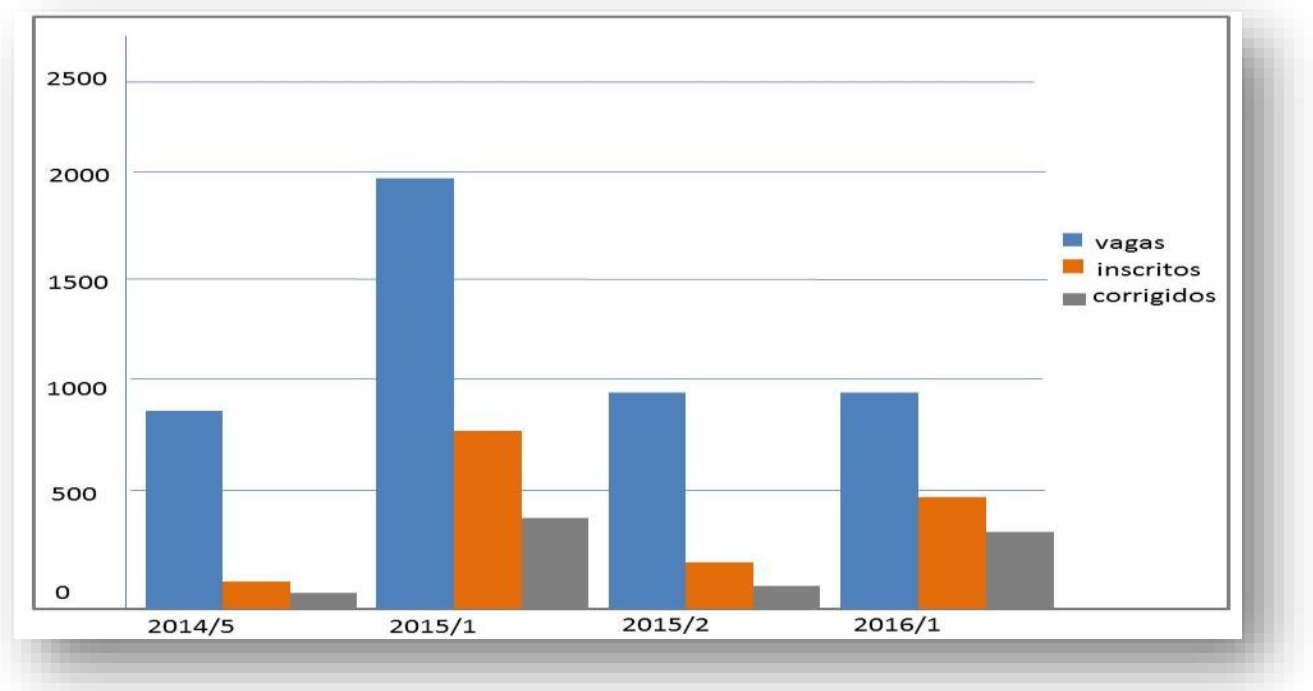

Fonte: Relatório analítico do Idiomas sem Fronteiras na Universidade Federal do Sul e Sudeste do Pará 2016

Podem se inscrever candidatos com nível A1, A2, ou seja, candidatos com pontuação de 310 a 677 pontos no TOEFL. Candidatos com nível igual a ou maior que B1 (acima de 459 pontos). Ao finalizar o curso, os certificados de participação são emitidos pelo Núcleo de Línguas do Idiomas sem Fronteiras/ARNI ao final de cada turma aos alunos aprovados.

Foi possível identificar através de dados obtidos no relatório analítico de 2016, o nível de proficiência dos candidatos que realizaram o exame desde 2014. A tabela 3, abaixo, apresenta o número de estudantes com resultados do TOEFL o total de estudantes no Campus de Marabá (válidos) que realizaram os estes: 621.

Tabela 3: Perfil de Proficiência Linguística dos alunos da Universidade Federal do Sul e Sudeste do Pará

\begin{tabular}{|c|c|}
\hline \multicolumn{2}{|c|}{ CAMPUS MARABA } \\
\hline NÍVEL & QTD \\
\hline A1 & 5 \\
\hline A2 & 542 \\
\hline B1 & 60 \\
\hline B2 & 13 \\
\hline C1 & 1 \\
\hline SEM NOTA & 8 \\
\hline
\end{tabular}

Fonte: Relatório Analítico Idiomas sem Fronteiras - Universidade Federal do Sul e Sudeste do Pará 2015/16

Os dados apresentados nos mostra que a maioria dos candidatos está classificada no nível A2 e a outra maioria no nível B1 e B2. Esta mensuração se dá pelos resultados obtidos nas provas aplicadas a variados candidatos desde as primeiras ofertas dos testes. Ressaltamos que todos os alunos inscritos nos cursos que foram analisados e apresentados neste trabalho estão inseridos nestes dados. 


\section{Relato da pesquisa nas aulas do NUCLI}

Esta pesquisa é um estudo qualitativo interpretativista. Conforme Maison (2002) considera que realizar abordagens interpretativista é naturalmente possível e comum, pois os pesquisadores podem conduzir etnografias interpretativista, o que difere este instrumento é o fato de o pesquisador ver pessoas, as suas interpretações, percepções, significados e entendimentos como fonte primária de dados. A observação é um dos métodos qualitativos do interpretativismo e para Bortoni-Ricardo (2008), a pesquisa qualitativa não busca experimentar as relações de causa e consequência entre fenômenos, e sim analisa os fenômenos sociais inseridos em um contexto:

[...] na pesquisa qualitativa, não se procura observar a influência de uma variável em outra. $\mathrm{O}$ pesquisador está interessado em um processo que ocorre em determinado ambiente e quer saber como atores sociais envolvidos nesse processo o percebem, ou seja: como interpretam (BORTONI-RICARDO, 2008, p. 34).

A coleta seguiu os passos necessários a sua definição, primeiro, a exploração do ambiente; segundo a decisão sobre a coleta dos dados, e seleção adequada para compreender e interpretar o tema proposto e terceiro a descoberta, a justificativa no contexto pesquisado. Segundo Ludke e André (1986), a aparelhagem instrumental nas pesquisas qualitativas é: a observação, a entrevista, o questionário e a análise documental. A entrevista é o instrumento pelo qual o pesquisador estabelece a interação com o pesquisado, além disso a entrevista é um encontro entre duas pessoas, a fim de que uma delas obtenha informações a respeito de determinado assunto, mediante uma conversação de natureza profissional.

O questionário é um instrumento de coleta de dados constituído por uma série ordenada de perguntas, que devem ser respondidas por escrito e sem a presença do entrevistador. Consiste em traduzir os objetivos da pesquisa em perguntas claras e objetivas. Esta pesquisa segue em concordância com os objetivos propostos na temática principal deste trabalho; analisar a concordância do ensino aprendizagem da Língua Inglesa por meio da abordagem ESP, nos cursos ofertados pelo Idiomas sem Fronteiras na Universidade Federal do Sul e Sudeste do Pará.

A pesquisa foi realizada em três turmas do NucLi, em três cursos específicos, nos quais são:

Curso 1) (C1) Oficina superintensiva de Leitura em Inglês Instrumental;

Curso 2) (C2) Prática de pronúncia em Língua Inglesa;

Curso 3) (C3) Oficina Superintensiva: Inglês com enfoque no cotidiano

Foram aplicadas entrevista as duas bolsistas graduandas do curso de Letras Inglesa, professoras destes cursos, aplicados aos discentes no ano de 2015 e 2016. Os instrumentos desta pesquisa são a observação qualitativa interpretativista em sala de aula e a entrevista aplicada a duas professoras bolsistas do programa. As observações foram em turmas de nível intermediário. Os cursos oferecidos pelo NucLi são cursos com duração de 16 horas. Cada curso propõe um tema voltado para as quatro habilidades do inglês, listening, reading; writing, e speaking. A coleta dos dados teve o objetivo de não interferir nas aulas e no comportamento dos alunos. O instrumento de observação utilizado foi diário de campo, observaram-se os alunos e os conteúdos aplicados em aula e a abordagem de ensino.

\section{Análise dos dados}

No primeiro curso, intitulado Oficina de escrita em inglês instrumental, notamos os temas trabalhados neste curso os quais foram: Articles and prepositions; Connectors; Adjectives and nouns; Pontuation; Adverbs and Adverbial phrases; Tag Questions; Compound Words; Word Order; Word Building; Verbal Times; Clauses; Spelling Rules; Irregular Verbs; Modal Verbs; Reported Speech; Interjections; Wishes and 
preferences; Passive Voice. Em uma das aulas observadas neste curso, foi trabalhada uma narrativa. A professora primeiramente colocou a narrativa em áudio para que os alunos buscassem identificar palavras que já conheciam; na segunda tentativa, colocou o áudio para que os alunos acompanhassem o áudio com o texto escrito em mãos.

A primeira proposta da professora ao colocar o áudio pela primeira vez foi para que os alunos compreendessem o contexto da história e identificasse palavras nas quais já conheciam principalmente os verbos no passado. Nesta atividade percebeu-se, pouca interação dos alunos em suas respostas, que se deu pela pouca compreensão na narrativa em áudio. A professora expressou sua percepção e reportou aos alunos que para o nível de inglês que eles tinham estava dentro da normalidade a pouca familiaridade com a narração do texto no primeiro impacto sem auxílio do texto escrito.

A professora na condução da atividade preocupou-se na terceira vez ao repetir a história em áudio com o auxílio do texto, fez uma pausa após cada parágrafo, para que os alunos acompanhassem o contexto e identificassem os verbos no passado em cada frase. A narrativa era um conto de halloween, além de trazer conhecimentos da cultura anglófona, que conformes Rivers $(1981)^{5}$, através da leitura o aluno amplia o conhecimento e compreensão da cultura dos nativos da língua, as suas maneiras de pensar, as suas atividades contemporâneas, e as suas contribuições para muitos setores da produção artística e intelectual. Além de o texto trazer elementos da cultura, foi trabalhada a gramática, a compreensão do texto com o listening. Como última atividade os alunos construíram textos utilizando os verbos no passado e após compartilharam seus textos em inglês com toda a turma.

Nesta aula foi possível perceber elementos condizentes com as necessidades dos alunos e seus objetivos em aprender inglês, visto que o ESP segundo Vilaça (2003) busca preparar o aluno para que ele utilize este idioma como instrumento para a realização de tarefas específicas que lhe são necessárias. Em um dos warm up feitos em sala, como na dinâmica serviu para desenvolver a conversação. Foi possível perceber nesta dinâmica, o nível de proficiência da fala e compreensão dos alunos para com o inglês pronunciado pela professora quanto para com o inglês pronunciado pelos próprios alunos.

Dessa forma a professora nesta aula percebeu uma necessidade dos alunos em geral, e traçar assim um perfil dos alunos presentes e alinhar sua didática ao material didático às propostas da abordagem EPS. Navarro e Gattolin (2016) consideram positiva a confecção dos próprios materiais didáticos em cada NucLi, pois assim, os professores bolsistas participantes da equipe do programa podem desenvolver seus potenciais como profissionais também neste quesito.

Nesta atividade de warm up, intitulada "Never have I even", a professora consegue reter de todos os alunos suas participações, pois pergunta a cada um a resposta. Isto se fez possível com a conduta da professora em deixá-los à vontade para aprenderem com seus erros, não permitindo que nenhum aluno desfavorecesse o esforço dos colegas, isto é positivo quanto à autoconfiança do aprendiz.

Navarro e Gattolin (2016), dizem que aliada à necessidade de conhecer o perfil dos alunos, os autores consideram que a metodologia a ser utilizada no ensino de inglês, visto às necessidades estabelecidas pelo Idiomas sem Fronteiras, em preparar os alunos para intercâmbios acadêmicos, exigiria um método que rápido atendesse as necessidades dos futuros estudantes no exterior. Com isso, as aulas do NucLi foram ofertadas em cursos de curta duração, por temas conforme cada ementa disposta no programa NucLi da Universidade Federal do Sul e Sudeste do Pará. Dessa forma, na experiência desses autores pareceu-lhes adequado para cada núcleo desenvolver seus próprios materiais didáticos pautados na teoria de ensino de línguas para fins específicos.

\footnotetext{
${ }^{5}$ Rivers Texto-fonte: "Through it they can increase their knowledge and understanding of the culture of the speakers of the language, their ways of thinking, their contemporary activities, and their contributions to many fields of artistic and intellectual endeavor".
} 
Quanto aos materiais utilizados em sala, as professoras preparam seus próprios materiais de cada curso, comumente, estas enviam o material a serem usados em cada aula, antecipadamente aos e-mails dos alunos, ou levam cópias dos conteúdos e distribuem nas aulas. Em todas as aulas nas quais foram observadas, não faltou material didático impresso para todas as atividades.

No segundo curso, denominado Prática de pronúncia em Língua Inglesa, foram adotados os temas: Phonetic symbols; Spelling; Word stress; Sentence Stress; Intonation; Rhythm; Word linking; Casual speech; Accent; Descriptions of the sound; Mouth positions; Voicing; Aspiration; Vowel Length; Syllables; Specific Sounds; Similar Sounds; Tongue twisters; Trouble Sounds; Telephone number pronunciation; Minimal pairs; Using music and videos. A professora trabalhou neste curso a pronúncia correta das palavras, através da fonética, utilizou o recurso dos áudios para a distinção de palavras com o mesmo som e escritas diferentes. Na primeira aula deste curso a professora trouxe para o warm up, com a dinâmica de jogo da forca, utilizando os vocabulários das cores e membros da família.

A aula voltou-se para estudar os sons das letras, e as atividades para o reconhecimento e a distinção dos sons nas palavras. Por exemplo, em uma das aulas foram trabalhados os sons de /I/E em palavras como pin - pen, chiks - check, wrist - rest, bill - bel. Os alunos puderam visualizar com o data show as palavras e ouvir os sons repetidamente. A professora explicou a igualdade dos sons e a diferença nas palavras. E nas atividades os alunos ouviram os sons e identificaram as palavras corretas. Percebeu-se que nesta atividade os alunos ficaram atentos e surpresos quanto à apresentação da fonética de língua inglesa. Muitos alunos não estavam familiarizados com os símbolos fonéticos. Foi perceptível a aceitação deles quanto à pronúncia, e maior resistência deuse quanto à transcrição fonética das palavras, com isto, não se prenderam tanto na transcrição fonética, mas entenderam a identificação das pronúncias.

A professora foi feliz ao trazer para sua explicação a importância na identificação das palavras, mas principalmente em fazê-los ouvirem as palavras e identificá-las pelos significados dentro de um contexto. Assim, notou-se que os alunos ficaram mais a vontade em compreender a relevância da fonética. A importância de trabalhar a fonética no método ESP se dá pela sua importância na compreensão do listening, este fator tem total valor na qualidade da compreensão principalmente na atividade de listen em testes de proficiência como o Toefl, entre outros. Já no terceiro curso, intitulado oficina superintensiva, deu-se enfase ao cotidiano. Os temas estudados foram, por exemplo, Self-introduction; Basic greetings; Greeting someone you know; Small talk; Hobbies; How is your day; Tomorrows Plan; Slangs; Idioms; Expressions; Chat Language; Apologies, excuses and promises; Helping People; Expressing Sympathy and Surprise; Giving Reasons and Making Suggestions; Personal questions; Phone Conversation; Common Subjects such as music and cinema; Directions and Places; Daily Routine; Colloquial and Informal Expressions e Using music and videos.

Os temas dispostos neste curso favoreceram os alunos a buscarem todo o vocabulário que eles já conheciam para realizarem as atividades. E buscarem novos vocabulários de cotidiano e situações da vida prática. Quanto a este ponto, conversação no cotidiano, remete os aprendizes a situações nas quais poderão estar envolvidos em diversos ambientes. Pôde-se conectar este curso a necessidades que terão no caso de futuro intercambistas e mesmo situações de recepcionar um estrangeiro em inglês.

Para Dudley-Evans e St. John (1998) é mais motivador o uso do ESP do que do inglês geral, para o ensino do inglês, pois a natureza do ensino EPS é buscar temas com relevância na relação custo eficácia que garantem com que os conteúdos programados sejam amplamente aceitos pelos alunos, alcançando assim com mais objetividade e rapidez seu aprendizado de inglês. Segundo estes autores as opiniões sobre a abordagem ESP, variam, entretanto, muitos alunos estão ansiosos por material e conselhos que os ajudem com seu aprendizado ou com as habilidades específicas em seus cursos, como exemplo, para conseguirem terem melhor aproveitamento em cursos, conferências de pós-graduação entre outros, buscam respostas mais direcionadas a preencherem as lacunas no seu processo de aprendizagem de uma língua. 


\section{Entrevistas com as professoras bolsistas}

Foram feitas três perguntas para as duas professoras bolsistas do NucLi da Universidade Federal do Sul e Sudeste do Pará. As professoras são graduandas do curso de Letras Inglesa desta IES, foram nomeadas conforme os critérios do edital de classificação, ambas obtiveram o perfil B1 de proficiência no teste do TOEFL. Seguem as perguntas:

1) Você acredita que a falta de material didático padrão não fornecido pelo Idiomas sem Fronteiras diminui a qualidade do ensino aprendizagem nas suas aulas?

2) Você seleciona seu próprio material didático, acredita que consegue ensinar bem inglês em conformidade com a abordagem EPS na escolha dos conteúdos didáticos?

3) Você acredita que ser professor do NucLi é uma oportunidade aos alunos graduandos de Letras Inglesa?

$\mathrm{Na}$ primeira pergunta a professora bolsista estagiária A, afirmou que a falta de material didático padrão não fornecido pelo Idiomas sem Fronteiras, não prejudica a qualidade do ensino em suas aulas. Afirmou que a maioria do material didático é selecionada por meio da internet. Em relação à segunda pergunta a bolsista estagiária $\mathrm{A}$, diz que selecionar o próprio material, ajudou a tornar as aulas mais dinâmicas e menos repetitivas. E conseguiu colher bons materiais, pois observou às necessidades dos alunos, uma dessas necessidades era prepararem-se para provas de proficiências e intercâmbios. Na terceira pergunta a bolsista estagiária $\mathrm{A}$, responde (Transcrição real): "Sim. Uma grande oportunidade de trabalhar as habilidades de ensino dos discentes de letras, conquistar a autoconfiança como professores, sem contar a ajuda financeira que também deve ser levada em conta".

Como consideração a bolsista estagiária A afirmou: "os alunos tiveram um ótimo desempenho nas aulas, pois começaram o curso sem dizer nada em inglês e ao fim já iam perdendo a vergonha em participar das aulas, mas não são todos os casos infelizmente". Alguns não tiveram tanta mudança. A bolsista estagiária A, afirma sempre dizer aos seus alunos que as aulas com apenas 4 horas de duração semanal para uma semana de 24 horas, estes não devem esperar aprender inglês somente em sala, precisam se dedicar para atividades extraclasses, considera ainda que o único método mais abrangente na universidade para o ensino de inglês seria inserir inglês nas grades de todos os cursos, pois assim os alunos ficariam mais estimulados a aprenderem o idioma.

A bolsista estagiária B, em resposta a primeira pergunta, afirma: (Transcrição real) "um material padrão não seria tão benéfico, visto que acarretaria em uma rotina monótona e, provavelmente, inibiria as habilidades criativas do professor". Na segunda pergunta a bolsista Estagiária B relata: (Transcrição real) "Acredito que sim". Já que dessa forma, consigo selecionar os temas e métodos a serem trabalhados de acordo com as necessidades dos meus alunos. Na terceira resposta a bolsista estagiária B, considera: (Transcrição real) "acredito que seja uma ótima oportunidade apenas para os alunos que já se sentem aptos a lecionar”. A bolsista estagiária B diz que os conteúdos aplicados em sala sempre foram baseados no ambiente do cotidiano, e por ser um tópico com o qual os alunos conseguiam se relacionar facilmente e, tendo sempre em mente o desempenho dos alunos quanto ao desenvolvimento de vocabulários, portanto ela avalia o desempenho de seus alunos com conceito ótimo.

Alguns alunos perguntavam por um material didático sequencial que fossem disponibilizados pelo professor de uma única vez. Dos três cursos observados as professoras enviavam para e-mail dos alunos todo o conteúdo no qual seriam trabalhadas em sala, em dias anteriores as aulas, e algumas outras atividades entregavam na hora da aula.

Os autores Augusto Navarro e Gattolin (2016) apontam através de estudo realizado na universidade Federal de São Carlos (UFSCar) pontos que consideramos relevantes em comparação a forma de organização do ensino de inglês nos cursos do NucLi na Universidade Federal do 


\section{Sul e Sudeste do Pará.}

$\mathrm{Na}$ UFSCar levou-se em conta a relação custo benefício no quesito de desenvolver o próprio material didático, sobre confeccionar material didático padrão para cursos rápidos, para não ter um custo alto para cursos rápidos. Os autores dizem que com esta decisão beneficiaram aos professores bolsistas, pois os próprios professores do NucLi selecionariam o material didático, com isto podiam mostrar seus potenciais como professores.

Sob este aspecto as professoras bolsistas do NucLi da Universidade Federal do Sul e Sudeste do Pará consideram um ponto positivo, no fato de elas próprias serem responsáveis por selecionarem o material didático dos cursos ministrados. Nos cursos analisados foram identificados a coerência com a abordagem ESP nos materiais didáticos utilizados em aula, visto ainda a coerência com a ementa criada pela coordenação do NucLi para os curso/hora.

\section{Considerações finais}

O NucLi Universidade Federal do Sul e Sudeste do Pará busca através dos cursos de inglês ir ao encontro dos objetivos do programa Idiomas sem Fronteiras, e a partir da abordagem adotada no ensino da língua inglesa ESP, atender aos participantes que possuem a finalidade de realizar intercâmbios e outros objetivos acadêmicos. Em relação à coerência na seleção dos materiais didáticos com a abordagem ESP, nós percebemos que nos cursos analisados as professoras buscaram corresponder à proposta do método adotado, aproximando-se do que dizem os autores Navarro e Gattolin (2016), as seleções desses materiais devem ser feitos cuidadosamente atentos a corresponderem às necessidades dos aprendizes. Desta forma, as ementas dos cursos analisados estavam em conformidade com necessidades dos aprendizes que tem como objetivos o aprendizado de inglês gradativo, com materiais selecionados para os fins de comunicação prática do cotidiano, compreensão e leitura.

Ainda que as ofertas dos cursos presenciais sejam de 16 horas a duração, e isto nos acreditou, implica em pouco tempo para o ensino e aprendizado da língua inglesa, estes cursos correspondem aos propósitos do programa. Foi possível notar nos participantes presentes dos cursos, interesse em aprender inglês, através da participação deles nas atividades em sala. Infelizmente, registramos na fala de uma das professoras do NucLi, "nem todos os alunos são perseverantes no seu aprendizado". Infelizmente a evasão nos cursos acontece, entretanto, é um aspecto também de núcleos de ensino do Idiomas sem Fronteiras de outras universidades.

Levantamos uma pergunta pertinente para as professoras instrutoras do NucLi; de que modo elas avaliariam seu ensino nas salas de aula. As professoras avaliaram de forma positiva e produtiva. Pois, mencionaram que a oportunidade em lecionar nesses núcleos agrega experiências. Além disso, elas entendem que ao fazerem comparações imediatas com o método de ensino adotado e observam o que é possível melhorar para alcançar maior interesse dos alunos.

Para o NucLi Universidade Federal do Sul e Sudeste do Pará, assim como para o ensino de línguas em geral no programa Idiomas sem Fronteiras, acreditamos que em conformidade ao que diz Navarro e Gattolin (2016), apesar da rede mundial de computadores, oferecer diversos materiais didáticos é importante observar os direitos autorais e encontrar formas de utilizar esses materiais autênticos sem ferir essas leis. Outro ponto que Navarro e Gattolin também mostram, é o pouco tempo para trabalhar na seleção de materiais, que requer dedicação de horas, pesquisa, revisão, sendo por vezes um trabalho repetitivo. Até o momento desta pesquisa os NucLi em geral não recebem materiais didáticos padronizados.

Acreditamos que tanto o programa, assim como as aulas presenciais do NucLi na Universidade Federal do Sul e Sudeste do Pará, tem conseguido corresponder aos objetivos gerais do Idiomas sem Fronteiras, entretanto é necessário aperfeiçoá-lo para alcançar um público maior; e, oferecer mais tempo de aula, disponibilizar mais professores, fixar salas para uso do NucLi em todos os campi da universidade de modo que os cursos do NucLi estejam presentes e atender a 
demanda da universidade. O método de abordagem ESP compreendeu-se ser uma abordagem de ensino apropriada aos objetivos do programa.

Percebemos ainda que se os cursos pudessem vir a contar com o sistema online MEO - My English, sendo que a universidade disponibilizaria estrutura digital, através dos laboratórios, e ainda os próprios participantes poderiam utilizar seus computadores pessoais, para a realização dos cursos online, vinculando o curso online ao curso presencial na universidade, ambos gratuitos agregariam mais qualidade e alcance no ensino e aprendizagem da língua. Como isto contribuiria no ensino dentro da abordagem ESP? As aulas nas quais fossem ministradas com o recurso do MEO traria a atividade complementar interativa e as aulas continuariam seguindo a estrutura de ensino na qual já utiliza a abordagem ESP. Como últimas considerações Lima e Moraes Filho (2016) argumentam que o Idiomas sem Fronteiras não é um programa que irá resolver todas as necessidades linguísticas do país, no entanto poderá contribuir para potencializar as IES no processo de internacionalização e de preparação linguística de profissionais de todas as áreas, com foco atento aos futuros professores da graduação de línguas estrangeiras e a comunidade interna.

\section{Referências}

BORTONI-RICARDO, S. M. O professor pesquisador: introdução à pesquisa qualitativa. 1. ed. São Paulo: Parábola Editoral, 2008

BRASÍLIA (Estado). Portaria no 973, de 14 de Novembro de 2014. Institui o Programa Idiomas sem Fronteiras e dá outras Providências. Brasília: Diário Oficial da União - Seção 1. No 222, p. 11, 17 de nov. 2014.

COLEÇÃO PERSPECTIVAS ATUAIS/EDUCAÇÃO. Quadro comum Europeu de referencia para as línguas - Aprendizagem, ensino, avaliação. Conselho da Europa. Asa Editores II, S.A. Porto Portugal. 2001. Disponível http://area.dge.mec.pt/gramatica/Quadro_Europeu_total.pdf. Acesso em: 20/11/2019.

DIAS. M. A. R.; MOROSINI, M. C. N, A.; SPELLER, P.; CAMARGO, M. S.; LÁZARO, A.; CUNHA, C. Fórum latino-americano de educação superior / Foro latinoamericano de Educación superior / organizadora: Marília Morosini. São Carlos: Pixel, 2015.

DUDLEY-EVANS, T; St. JOHN, M. J. Developments in English for Specific Purposes. A multidisciplinary approach. Cambridge: Cambridge University Press, 1998. Disponível em: http://assets.cam bridge.org/97805215/96756/excerpt/9780521596756_excerpt.pdf. Acesso em: 22/11/2016.

HUDZIK, J. K. Executive Summary. Comprehensive Internationalization. From Concept to Action. Editors' Notes. Ano 2011. Disponível em: http://ecahe.eu/w/images/1/1f/Comprehensive_ Internationalization_-_NAFSA.pdf. Acesso em: 13/06/2016

HUTCHINSON, T.; WATERS, A. English for Specific Purposes: a learning-centred approach. Cambridge: Cambridge University Press, 1987. Disponível em: http://assets.cambridge.org/97805213/ 18372/excerpt/9780521318372_excerpt.pdf. Acesso em: 15/09/2016.

KNIGHT, J. Universidades que apostam na Internacionalização. Extra Classe.Org.Br 22/09/2014. Disponível em http://www.extraclasse.org.br/edicoes/2014/07/universidades-apostam-na-interna cionalizacao/. Acesso em: 16/06/2016.

LAMRI, C. E. An Introduction to English for Specific Purposes (ESP). University - Tlemcen. 2016.

LUDKE, M.; ANDRÉ, M. E. D. A. Pesquisa em educação: abordagens qualitativas. São Paulo: EPU, 1986.

MASON, J. Qualitative Researching. Londres: Sage, 1996. Disponível em http://www.sxf.uevora. pt/wp-content/uploads/2013/03/Mason_2002.pdf. Acesso em: 15/12/2016.

RELATÓRIO ANALÍTICO, IES; Universidade Federal do Sul e Sudeste do Pará, UNIFESSPA, Programa Idiomas sem Fronteiras. Marabá, Pará. 2016.

RIVERS, W. M. Teaching foreign-language skills. 2.ed. Chicago: The University of Chicago Press, 1981. Disponível em: http://www1.udel.edu/eli/educ647/rivers/Rivers2.pdf. Acesso em: 
$17 / 11 / 2016$.

SARMENTO, S; KIRSCH, W. Inglês Sem Fronteiras: Uma Mirada ao contexto de Prática pelo prisma da formação de professores. English Without borders: A glance at the context of Practice Through the prism of teacher development. Florianópolis. 2015. Disponível em: http://dx.doi.org/10.5007/2175-8026.2015v68n1p47. Acesso em: 12/06/2016.

SARMENTO, S; LIMA, D; MORAES FILHO, W; NAVARRO. E. G. S.; BARBOSA,

W.; BLUM, A. Do Inglês sem Fronteiras ao Idiomas sem Fronteiras, a construção de uma política linguística para a internacionalização. Editora UFMG, 2016.

VILAÇA, M. L. C. O processo de avaliação e elaboração de materiais didáticos para cursos de inglês para fins específicos. In: Revista de Letras do Instituto de Humanidades da UNIGRANRIO 1. Duque de Caxias, Unigranrio Editora, 2003. Disponível em: www.unigranrio.br. Acesso em: 10/09/2016.

ZICMAN, R. Internacionalizando a universidade. Ficha catalográfica elaborada pela Biblioteca Reitora Nadir Gouvêa Kfouri/PUC-SP. São Paulo, EDUC, 2007.

Recebido em: 17/08/2017

Aceito em: 13/05/2018 